\title{
SISTEMA DE INFORMAÇÕES GEOGRÁFICAS PARA PROJETOS DE SISTEMAS DE ESGOTAMENTO SANITÁRIO NO CAMPUS DA UFSB
}

\author{
AUTOR: ISABELLA SILVEIRA SANTOS \\ ORIENTADOR: MARCELO SOARES TELES SANTOS
}

Resumo: Este trabalho teve como objetivo geral desenvolver um Sistema de Informações Geográficas (SIG) para a gestão de Sistemas de Esgotamento Sanitário do Campus da UFSB. Para isso, o software Quantum GIS (QGIS) foi utilizado na geração e integração dos mapas temáticos (indicadores cartográficos) e das respectivas tabelas de atributos (indicadores descritivos) associadas, de acordo com as informações necessárias aos projetos de esgotamento sanitário do Campus. Os mapas temáticos foram elaborados a partir do mapa de uso e ocupação do solo do Campus, o qual foi gerado a partir de imagem aérea digital georreferenciada. Esses indicadores foram cadastrados no SIG de tal forma que puderam ser relacionados espacialmente. Por exemplo, no mapa de edificações foram inseridas informações descritivas como nome da edificação, número de usuários, demanda hídrica, número de Banheiros, geração estimada de esgotos sanitários, entre outras importantes aos projetos de esgotamento sanitário. Dessa forma, o presente trabalho compreendeu as atividades relacionadas com a implantação do SIG, especificamente na geração do mapa de uso e ocupação do solo e na criação do banco de dados específico para a gestão de sistemas de esgotamento sanitário. Como a continuidade do trabalho, serão obtidas e inseridas as informações descritivas coletadas em campo e na UFSB, assim como realizadas análises espaciais relacionadas com os sistemas de esgotamento sanitário.

Palavras-chave: Geoprocessamento, Saneamento Básico, Ordenamento Territorial, UFSB. 